\title{
Planet Earth Capacity Factor and New Look Criteria
}

\author{
Serdar Eser Erturan ${ }^{1}$, Huseyin Murat Cekirge ${ }^{1,2}$, Richard Stanley Thorsen ${ }^{2}$ \\ ${ }^{1}$ Mechanical Engineering, City College of New York, City University of New York, New York, USA \\ ${ }^{2}$ Mechanical Engineering, New York University, Brooklyn, USA
}

Email address:

serturan@ccny.cuny.edu (S. E. Erturan), hmcekirge@nyu.edu (H. M. Cekirge)

\section{To cite this article:}

Serdar Eser Erturan, Huseyin Murat Cekirge, Richard Stanley Thorsen. Planet Earth Capacity Factor and New Look Criteria. American Journal of Modern Energy. Vol. 6, No. 2, 2020, pp. 59-64. doi: 10.11648/j.ajme.20200602.12

Received: March 13, 2020; Accepted: May 6, 2020; Published: May 19, 2020

\begin{abstract}
The paper presents and facts and indicators of the Planet Earth capacity factor considering questions of existing human activities' safety and sustainability. These questions can be extended for advancing and developing our home planet without encountering a dilemma and future generations and civilization developments' sufferings because of our movements. In order to get positive answers to these questions, we definitely need to improve our technological skills. It might be an appropriate explanation to understand our current timeline. As the 2020 COVID-19 pandemic demonstrates, nature can quickly become a formidable foe-particularly if humans are caught unprepared. Although Earth's ideal conditions have provided humans with a perfect environment to thrive socially and economically, her natural resources are not limitless and her natural balances are delicate. It is critical to begin developing solar technology to meet the human race's energy needs. The human race currently meets its energy needs mainly through fossil fuels. But not only are fossil fuel reserves limited but also excessive reliance on fossil fuels can cause long-term environmental damage. On the other hand, solar energy is bountiful, free and clean. As such, solar energy is a great alternative source of energy that will ensure that future generations enjoy a hospitable planet and healthy and economically stable living conditions. Planet Earth supports our current lifestyles, but there are obvious indications of unusual changes in her cycles. Only recently have we begun to consider plans regarding Earth's capacity; historically, we have mostly considered local environmental factors. Unfortunately, the time for only thinking of local factors has passed - we must consider the planet's capacity for continued human survival in order to create a sustainable lifestyle. As humans, we believe that we live in some sort of "infinite time spiral" - that is, we believe that the human race will live forever - but this is simply illusionary cortical brain activity. The paper also presents mitigation measures such as searching and developing new criteria in the Concentrated Solar Power (CSP) tower system, combined cycle configuration; Brayton Cycle, Rankine Cycle, Thermal energy storage (TES) and Thermal Water Desalination system.
\end{abstract}

Keywords: CSP, Solar Desalination, TES, Thermal Energy Storage, Air Cavity Receiver, DSG

\section{Fact and Indications}

If a glass is completely full, even a drop can overflow, so no matter how big or how small the cup is. The Planet Earth is not owned by us and it has been here over 4.3 billion years and it will be longer than us. In order to continue our civilization and look at galactic journeys, we must respect the planet Earth and start preparing new outlook criteria for a sustainable future. The paper has two folds:

A. First Fold: The Planet Earth Capacity Factor, Facts and Indications

This study paper is about where the critical line is and how to be sensitive and collective to new models. New look criteria require awareness, learning and not being afraid of the facts. The planet Earth supports and cares about our lifestyle, but there are clear signs of unusual changes in its cycle. We have not considered the capacity factor of the planet Earth until today. As human nature, we think we live in an infinite time spiral, but this is just misleading cortical brain activity. But the truth is that the growing human population and consumption habits require awareness to manage our new outlook civilization needs. "Dynamic Facts and Indications" are against the sustainable development ability of our civilization. It is necessary to change our habits and keep our technologies effective for an unknown fate. Our current lifestyle and business development styles are not sustainable! For a hopeful future, we can break the old walls 
and look at the new criteria of the new era.

The indications and facts listed are real and calculated by many reliable scientists. Controversial discussions will continue and the issue is not "who is right or wrong". The current dynamic algorithm is forcing planet Earth to turn its cycle into a destructive period. The main concern is to create a comprehensive and flexible view to show dynamic indications and facts and enlighten your awareness.

Facts: Carbon Fuels Consumption and Extreme Foot Print, Changing the Planet Earth Surface, Polluting the Oceans, Polluting the Soil, Mass Agricultural and Livestock Activities, Increasing Human Population.

Indications: Extreme Climatic Weather Conditions, Changes in Magnetic Fields, Changes of the World Axis, Extinctions of the Species, Atmospheric Abnormality, Abnormal Ocean Currents.

B. Second Fold: Searching and Developing New Look Criteria

The purpose of this study is to demonstrate the reduction of the electricity price below 5 US $\notin / \mathrm{kWh}$. within the combine cycle next generation Concentrated Solar Power (CSP) tower system. For this goal, the paper suggests an integrated facility, includes low cost single tank sensible thermal energy storage (TES). The idea is combining existing technologies within a touch of the new look criteria.

The proposed design configuration next-gen (CSP) tower system is the combined Brayton Cycle + Rankine Cycle + Thermal Energy Storage (TES) + Thermal Water Desalination system. The process schematic is; heated air through air cavity tube receiver to run the gas turbine (Brayton Cycle) and hot air exhaust output to heat exchanger to steam production. Steam from the heat exchanger to charge the TES, and TES to charge second turbine (Rankine Cycle) and charge to the thermal desalination unit. Kreith and Goswami [1], Boerema et al. [2], Law et al. [3, 4].

Our team has built and operated Greenway CSP tower plant, NREL-GREENWAY [5] and all the relevant knowhow and data is from Greenway CSP tower plant. Short description of the Mersin CSP tower plant; the field capacity $5 \mathrm{MW}_{\mathrm{t}}$. The system boiler is Direct Steam Generator (DSG), $10 \mathrm{MW}_{\mathrm{t}}$ single tank sensible TES, $1 \mathrm{MW}_{\mathrm{e}}$ steam turbine, the tower height is 50 meters, and the field has 510 Intelligent wireless heliostats. Greenway CSP plant was operated eight years. The smart plant operation system developed and tested during that time. The plant operating control system philosophy based on real-time data sharing within dynamic solar energy input configurations and interactive synchronized auxiliary systems. One of our past main achievement is the heliostat production cost; less than 100 US $\$ / \mathrm{m}^{2}$. Including simple site assembly, erections and startup calibrations.

The CSP solar technology is developing rapidly. However, in order to expand this technology in electricity generation, it is necessary to develop high efficiency and low-cost systems. Usually, steam turbines (Rankine Cycle) are used for electricity generation at the CSP plant, so efficiencies are limited. This causes low efficiency in CSP plants. It is also very important to present new ideas while reaching the targeted cost. Combined cycle electricity production will be applications. It is clear that the future energy sources will be the CSP tower design for renewable systems and especially for electric energy production. The production cost of this energy is essential for the use and expansion of the CSP as a reliable energy source. In addition, reducing carbon emissions will have a positive environmental impact when dealing with power and thermal desalination.

\section{Technical Description, Design, Innovation, and Impact}

\section{A. System description:}

Detailed feasibility studies were made for the proposed CSP facility within the scope of the paper's project. In particular, if the field is built in East Cost, the operation hours there will be over 3000 available solar hours per year. The CSP tower field area requires 1500 heliostats and correspond area to $25.000 \mathrm{~m}^{2}$ and tower height 50 meters. The electricity generation comes from the gas and steam turbine units in total of $6 \mathrm{MW}_{\mathrm{e}} ; 4.7 \mathrm{MW}_{\mathrm{e}}$ from the gas turbine and $1.3 \mathrm{MW}_{\mathrm{e}}$ from the steam turbine. Annual productions of the plant; $20.000 \mathrm{MWh}_{\mathrm{e}} / \mathrm{y}$ and $365.000 \mathrm{~m}^{3} / \mathrm{y}$ fresh water.

1) Heated air through SIC air cavity tube receiver to $\left(715^{\circ} \mathrm{C}\right)$ and 13 bars will be sent to the First Turbine (Brayton Cycle) to generate electricity made in this uniquely designed CSP-Tower facility with both together.

2) Hot air $(545 \mathrm{C})$ from the exhaust of the first turbine the hot air gas turbine (Brayton Cycle) and the steam turbine.

Within the scope of the paper it is aimed to increase efficiency by using both gas turbine and steam turbine cycles. When success factors are discussed for the targeted price, it will enable field experts to use the combined steam turbine and gas turbine cycles of their future designs. Both TES and higher efficiency will help the paper for achieving its goals at an acceptable cost and efficiency.

The combine-cycle design improves space efficiency. If two CSP-Tower facilities with the same number of heliostat and locations are compared in terms of efficiency and electricity generation, this unique combine-cycle facility appears to have reached the target cost. One other critical success factor is the development of the base-load TES system.

One of the most efficient and versatile solar energy fields is the CSP tower. CSP tower with TES design is capable of using super-heated steam in any industrial application. As; base-loaded power plants, hybrids to any carbon-based power plant, thermal water desalination and any form of steam used in the most practical. Acceptance and attention will take place within a low LCOE (Levelized Cost of Energy). Our current studies show that we can produce $0.002 \mathrm{US} \$ / \mathrm{kg}$ steam cost. We will share our real-time CSP tower experience to discover highly efficient combined cycle system configurations. Therefore, existing uncertainties that prevent 
the implementation of these systems at various scales will be overcome. The purpose of this study will be a valuable guide for the commercial (Brayton Cycle) will be the source to heat exchanger to super-heated steam production.

3) Steam from output of the heat exchanger will charge the single tank sensible Thermal Energy Storage (TES)

4) TES, will supply the required steam to Second Turbine (Rankine Cycle) for to generate electricity.

5) Thus, when the sun shines, electricity production will be done together with First Turbine (Brayton Cycle) and Second Turbine (Rankine Cycle), and also the thermal storage system will be charged.

6) When the sun does not shine, the thermal storage system will discharge and only the Second Turbine (Rankine Cycle) will produce electricity. While TES charging the Rankine Cycle efficiency will be limited with in turbine capacity.

7) Thermal desalination unit will be charged from steam turbine exhaust heat and necessary heat balance will be regulated from TES within the sprinkle steam reduction method.

8) To higher efficiencies and balancing the system conditions may be requires the limited natural gas utilization.

B. Heliostat Field, Plant Core Software, Data Management and Process controls

1) 1500 heliostats each heliostat $16 \mathrm{~m}^{2}$ total field 24,000 $\mathrm{m}^{2}$. Design data of the heliostat field for engineering analysis is given in Figure 1.

2) Average thermal capacity $10 \mathrm{MW}_{\text {th }}$, Peak times capacity $12.8 \mathrm{MW}_{\text {th }}$ (annual hours $3000 \mathrm{MW}_{\text {th }} / \mathrm{y}$ ). The production hours and the power are calculated for the field designed calculations shown in Figure 2. The seasonal average thermal energy production graph was created by taking into consideration the design data and seasonal working hours shown in Figure 3.

3) Intelligent heliostat PCB. (process control board)

4) Hybrid secured wireless heliostat communications. (Omni and Mesh broadcasting topology)

5) Integrated real time field data management system.

6) Plant core software integrated auxiliaries to monitors the plant performance.

7) Auxiliary system configurations; motion control PCB, digital and optical heliostat calibration system, cloud detection system, thermal cameras, weather station system, embedded wireless communication system, dynamic field solar input calculation system, thermal SCADA system, TES control system.

\section{Air Cavity Receiver}

Although Silicon Carbide (SIC) ceramics have been considered for CSP receiver tubes by the CSP industry in the past; although there is reluctance on the part of the commercial CSP industry. This product has central layer that is using micron sized SIC fibers dispersed within a SIC matrix, Krenkel [6]. This composite layer surrounds an inner monolithic layer providing fluid containment and the state of being airtight and not brittle and exhibit a stress strain behavior similar to ductile metals, with a graceful failure mode when overloaded. Testing large SIC CMC components (Channel Boxes for Boiling Water Reactors as examples) have demonstrated an extraordinary tolerance to mechanical shock. Thermal shock testing TRIPLEX clad from $1000^{\circ} \mathrm{C}$ to room temperature has also demonstrated robust behavior. In addition, independent tests by the Karlsruhe Institute of Technology in Germany demonstrated robust performance under thermal shock from $2000^{\circ} \mathrm{C}$ to room temperature. With high temperature, high solar radiation emissivity and light design, the receiver will ensure that the field reaches the desired yield.

\section{Thermal Energy Storage (TES)}

TES, the project of the proposed paper in the system, will implement the design and pilot scale implementation of the availability in concentrated solar energy systems. Limitations in solar applications is that there are not many compatible plants with the grid system. Therefore, current uncertainties prevent these systems from being applied on a large scale. In pilot implementation, simple steam production supported by the innovative TES in the project of this study will be an example of commercial applications. CSP technology is developing rapidly; however, it has become necessary to develop high efficiency and low-cost systems in order to use this technology more in electricity production. One of the most important features is the development of systems that are compatible with the grid network system. This compatibility is only possible with appropriate TES integration. The CSP tower can reach higher temperatures and significantly increase the total energy conversion. Existing TES systems are built using molten salt systems. Therefore, the stored heat is transferred from the molten salt circulating between the tower and the cold and hot tank to the primary stream from the heat exchangers to produce steam. There are still serious problems in this type of storage systems due to the molten salt circulation. The project of the proposed paper aims at a facility that is an alternative to these systems which are operated commercially but cannot be competitive in the electricity market due to high operation and investment costs. In addition, it is aimed to develop a simple and innovative design based on precise heat storage. The proposed sensible single tank heat storage system consists of a combination of evaporator and two superheater units. Low-cost filling material will be used in heat storage environment and overheating tanks. The evaporator operates at $290^{\circ} \mathrm{C}$. When the pressurized steam is obtained from the steam drum in the evaporator section, the saturated steam will be transferred to the super steam production storage section to reach the superheated temperature of $545^{\circ} \mathrm{C}$. The engineering design concept is based on the old-fashioned heat recovery boiler system. The evaporator and super steam storage units are intended to be efficient and low-cost operations in accordance with the steam turbine conditions in the CSP tower area. Advantages; simplicity, maintenance free, durable, economical and proven centuries-old design. In this context, concentrated solar technology is also compatible with the development of innovative industrial applications and the development of a high temperature thermal storage 
system, Cekirge, Erturan and Thorsen [7].

E. The Thermal Desalination System

The thermal desalination systems units have been in the commercial market for decades. Our system design concept is plug and run, using the readymade unit as a condenser and placed at end of the Rankine cycle turbine. Delyannis [8], Khawaji [9], Al-Shammiri and Safar [10], Warsinger [11] Crittenden et al. [12, 13] and Cekirge, Erturan and Thorsen [14]. A "Multi-Effect Plate Evaporator (MEP)" is considered, and the MEP desalination process consists of a series of evaporation and condensation chambers known as effects. Each effect is fitted with heat transfer, and in the plate channels of an effect, seawater on one side is heated up and partially evaporated to distillate vapor, which is used in the next effect; on the other side, the distillate vapor from the previous effect is condensed, giving up its latent heat, into pure distillate. By maintaining a partial pressure difference across the effects, the process is able to yield maximum efficiency from available low- grade thermal energy sources. The brine that is output from the desalination unit will be processed to obtain precious minerals with Zero Liquid Discharge (ZLD) technologies. The fresh water output from the desalination unit will be for public consumption and utilization. Thermal desalination is superior to this and other methods of desalination for a number of reason, first, unlike these plants that burn fossil fuels, a thermal desalination plant runs entirely on solar energy and the steam that it generates during the desalination process, Further, a solar thermal desalination plant can operate and produce water far more cheaply than the current technology. Thus, a solar thermal desalination plant provides the environmental benefit of a reduced the carbon footprint, lessens the United States' dependence on fossil fuels, and provides water to the American public at lower costs. Widespread commercialization of the thermal desalination process also addresses a critical, life-and-death issue namely, the scarcity of fresh water in various parts of the country. Indeed, the growth of the U.S. population, coupled with lengthy droughts, has created significant fresh water shortages in certain states. where there are no water storages. The fresh water that is output of the solar desalination unit will be for public utilization. The brine (excessively salty water) that is output of the desalination unit will be processed for to obtain precious minerals with Zero Liquid Discharge (ZLD) technologies. Also, ZLD is a direct solution to problematic residuals. The goal is lower the cost less than $1 \mathrm{US} \$ / \mathrm{m}^{3}$.

The detailed cost and modified cost analyses for electricity production and desalination can be found Burenstam-Linder [15], Manzhos [16] Arroyo et al. [17] and Cekirge and Erturan [18].

\section{GREENWAY CSP POWER PLANT}

\begin{tabular}{|c|c|c|c|c|}
\hline Engineering Analysis & Inputs & & Outputs & \\
\hline \multicolumn{5}{|l|}{ INPUT Calculation Summary } \\
\hline & Value & Unit & & \\
\hline \multicolumn{5}{|l|}{ FIELD SIZE PARAMATER } \\
\hline Number of Heliostat & 1500 & Piece(s) & \multicolumn{2}{|c|}{ matlab modelling } \\
\hline Single Heliostat Surface Area & 16 & $m^{\wedge} 2$ & ref size & \\
\hline Total Mirror Surface Area & 24000 & $\mathrm{~m}^{\wedge} 2$ & & \\
\hline \multicolumn{5}{|l|}{ WEATHER PARAMETERS } \\
\hline DNI Threshold & 400 & $\mathrm{Wh} / \mathrm{m}^{\wedge} 2$ & & \\
\hline Direct Normal Irradiation For Production limit & 950 & $\mathrm{Wh} / \mathrm{m}^{\wedge} 2$ & & \\
\hline Wind Threshold & 0 & $\mathrm{~m} / \mathrm{s}$ & & \\
\hline PEAK EFFICIENCY PARAMATERS & & & \multicolumn{2}{|c|}{ Average Efficiency Parameters } \\
\hline Reflectivity Efficiency & $92,0 \%$ & & & $92,0 \%$ \\
\hline Cosine Efficiency & $79,7 \%$ & & & $76,1 \%$ \\
\hline Atmospheric Attenuation Efficiency & $95,5 \%$ & & & $94,1 \%$ \\
\hline Blocking \& Shadowing Efficiency & $97,3 \%$ & & & $93,2 \%$ \\
\hline Total Field Efficiency & $68,1 \%$ & & & $61,4 \%$ \\
\hline Mirror Cleanliness & $95,0 \%$ & & & $95,0 \%$ \\
\hline Pipe \& Thermal Efficiency & $98,0 \%$ & & & $98,0 \%$ \\
\hline Boiler Efficiency & $87,0 \%$ & & & $87,0 \%$ \\
\hline Thermal Efficiency & $55,1 \%$ & & & $49,7 \%$ \\
\hline
\end{tabular}

Figure 1. Engineering analysis. 


\begin{tabular}{|c|c|c|c|c|c|c|c|}
\hline CALCULATION OF OPERATING HOURS \& ENERGY PRODUCTIC & Value & Unit & & & & & \\
\hline Sample Year Production Hour & 3029 & Hour & & & & & \\
\hline Hourly Thermal Energy (Without Losses) & 22,80 & MW & & & & & \\
\hline Hourly Thermal Energy Production (peak) & 12,57 & MW & & & & & \\
\hline Turbine Efficiency & $22.0 \%$ & & & & & & \\
\hline Electricity Production (peak) & 2,77 & MWh & & & & & \\
\hline Operating Hours For: & Summer & $\begin{array}{l}\text { Spring \& } \\
\text { Autumn }\end{array}$ & Winter & $\begin{array}{l}\text { Total annual } \\
\text { operating hours }\end{array}$ & Unit & & \\
\hline Operational Capacity ( $\%$ of total) $20 \%$ & 30 & 44 & 51 & 125 & h & & \\
\hline Operational Capacity ( $\%$ of total) $40 \%$ & 70 & 159 & 48 & 277 & h & & \\
\hline Operational Capacity (\% of total) $60 \%$ & 196 & 300 & 95 & $\$ 91$ & h & & \\
\hline Operational Capacity ( $\%$ of total) $80 \%$ & 305 & 430 & 180 & 915 & h & & \\
\hline Operational Capacity (\% of total) $100 \%$ & 334 & 575 & 212 & 1121 & h & & \\
\hline Total operating hours (yearly) & 935 & 1508 & 586 & 3029 & h & & \\
\hline Thermal Power Production: & Summer & $\begin{array}{l}\text { Spring \& } \\
\text { Autumn }\end{array}$ & Winter & $\begin{array}{c}\text { Thermal Power } \\
\text { produced }\end{array}$ & Unit & $\begin{array}{l}\text { Total Thermal } \\
\text { Energy produced }\end{array}$ & Unit \\
\hline Operational Capacity (\% of total) $20 \%$ & 2,53 & 2,39 & 1,74 & 2,16 & MW & 0,27 & GWh \\
\hline Operational Capacity (\% of total) $40 \%$ & 5,44 & 5,32 & 5,06 & 5,31 & MW & 1,47 & GWh \\
\hline Operational Capacity ( $\%$ of total) $60 \%$ & 7,64 & 7,66 & 7,66 & 7,65 & MW & 4,52 & GWh \\
\hline Operational Capacity ( $\%$ of total) $80 \%$ & 10,13 & 10,16 & 10,09 & 10,14 & MW & 9,28 & GWh \\
\hline Operational Capacity (\% of total) $100 \%$ & 12.20 & 12.19 & 12.11 & 12.18 & MW & 13.65 & GWh \\
\hline Average Thermal Power Production & 9,75 & 9,70 & 9,29 & 9,64 & MW & 29,19 & GWh \\
\hline
\end{tabular}

Figure 2. Calculation of production hours and power.

\section{Seasonal Operation Hours for every Performance Points}

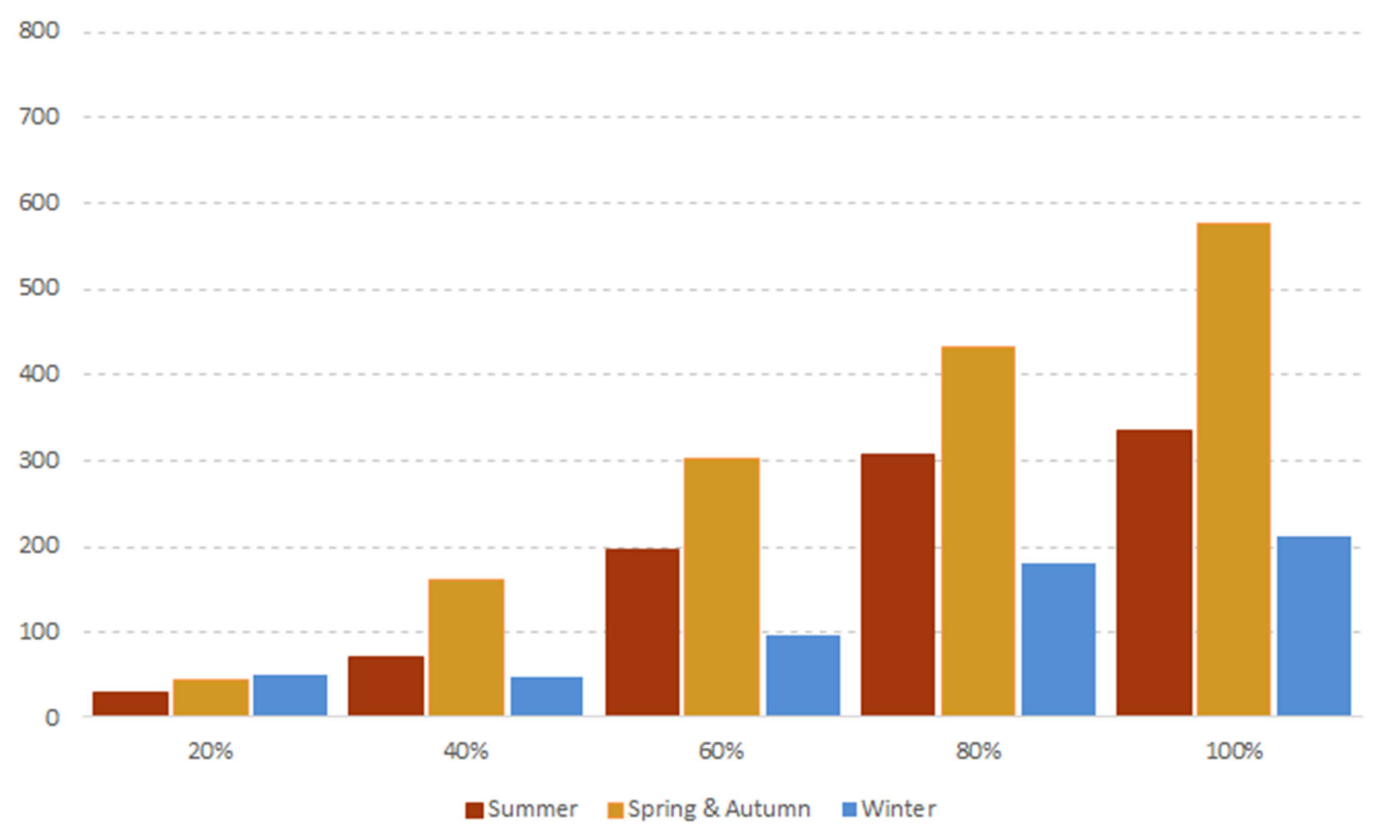

Figure 3. Seasonal operation hours for every performance points.

\section{Conclusions}

The impacts are:

1) High efficient and low-cost renewable power plant design.

2) Multipurposed combine cycle philosophy.
3) Old fashion proven low-cost TES design.

4) Reduction of the carbon emissions.

5) To achieve the highest efficiency rate in the simplicity.

6) The overall plant efficiency is aimed to be $65 \%$.

7) The impact will be revolutionary.

The beneficial impacts of CSP technology cannot be underestimated. Currently, Earth's fossil fuel reserves are 
being depleted and burning fossil fuels poses environmental challenges. Considering the limits of the human population and its consumption habits requires management of the demands of a modern civilization. The existing habits of mankind are needed to change; and must keep our technologies effective and sustainable to navigate an unknown future. The next stage of human civilization must look for new ways to develop into a higher-tolerance species. We must teach our citizens how to live on this planet through a new age perspective. These requirements are a part of this new "Planet Earth User Guide." This user guide may help us understand the current situation of our planet and the forces leading Earth into a destructive cycle. Having hopes for the future depends on changing old habits and evolving into a species that survives sustainably in the new age. This situation is now more critical and demonstrative if the 2020 COVID-19 pandemic is considered. Solar energy is free, bountiful and clean. Transitioning to solar energy will offer a clean alternative energy source, and it is the essential part of the "Planet Earth User Guide."

\section{References}

[1] Kreith, Frank and Goswami, D. Yogi ed., Handbook of Energy Efficiency and Renewable Energy, CRC Press, 2007.

[2] Boerema, Nicholas, Morrison, Graham, Taylor, Robert and Rosengarten, Gary, High temperature solar thermal centralreceiver billboard design, Solar Energy. 97: 356-368. doi: 10.1016/j.solener, 2013.

[3] Law, Edward W., Prasad, Abhnil A., Kay, Merlinde and Taylor, Robert A., Direct normal irradiance forecasting and its application to concentrated solar thermal output forecasting A review, Energy. 108: 287-307, doi: 10.1016/j.solener.2014.

[4] Law, Edward W., Kay, Merlinde; Taylor and Robert A., Calculating the financial value of a concentrated solar thermal plant operated using direct normal irradiance forecasts, Solar Energy. 125: 267-281, doi: 10.1016/j.solener.2015.

[5] NREL-GREENWAY, https://solarpaces.nrel.gov/greenwaycsp-Mersin-tower-plant, 2012.

[6] Krenkel, W., ed. Ceramic Matrix Composites: Fiber Reinforced Ceramics and their Applications 1st Ed., Wiley VSH, 2008.

[7] Cekirge, H. M, Erturan, S. E., Richard, R. S., The CSP
(Concentrated Solar Power) Plant with Brayton Cycle: A Third Generation CSP System. American Journal of Modern Energy. Vol. 6, No. 1, 2020, pp. 43-50. doi: 10.11648/j.ajme.20200601.16, 2020

[8] Delyannis, E., "Historic background of desalination and renewable energies," Solar Energy, 75 (5), 357-366, 2003.

[9] Akili D. Khawaji, a. d., Ibrahim K. Kutubkhanah, I. K., and Wie, Jong-Mihn, "Advances in seawater desalination technologies", Desalination. 221 (1-3): 47- 069. doi: 10.1016/j.desal.2007.01.067, March 2008.

[10] Al-Shammiri, M. and Safar, M., "Multi-effect distillation plants: state of the art". Desalination, 126 (1-3): 45-59. doi: 10.1016/S0011-9164(99)00154-X, November 1999.

[11] David M. Warsinger, Emily W. Tow, Kishor G. Nayar Laith A. Maswadeh and John H. Lienhard V, "Energy efficiency of batch and semi- batch (CCRO) reverse osmosis desalination". Water Research, 106: 272- 282. doi: 10.1016/j.watres.2016.09.029, 2016.

[12] John Crittenden, Rhodes Trussell, David Hand, Kerry Howe and George Tchobanoglous, Water Treatment Principles and Design, 2nd ed. John Wiley and Sons. New Jersey. ISBN 0471-11018-3, 2005.

[13] Argyris Panagopoulos, Haralambous, Katherine-Joanne and Loizidou, M., "Desalination brine disposal methods and treatment technologies - A review". Science of the Total Environment. 693: 133545, doi: 10.1016/j.scitotenv.2019.07.351, 2019.

[14] Cekirge, H. M, Erturan, S. E., Richard, R. S., CSP (Concentrated Solar Power) - Tower Solar Thermal Desalination Plant. American Journal of Modern Energy. Vol. 6, No. 2, 2020, pp. 51-58. doi: 10.11648/j.ajme.20200602.11

[15] Burenstam-Linder, C., Levelized Cost of Electricity (LCOE) and its limitations, available at, https://heatpower.com/news/renewable-energy/levelized-costof-electricity-lcoe-and-its-limitations/, 2017.

[16] Manzhos, Sergei, On the Choice of the Discount Rate and the Role of Financial Variables and Physical Parameters in Estimating the Levelized Cost of Energy, Int. J. Financ. Stud., 1 (3), 54-61; doi: 10.3390/ijfs1030054, 2013.

[17] Arroyo, J. and Shirazi, S., Cost of Brackish Groundwater Desalination in Texas, Texas Water Development Board, September 2012.

[18] Cekirge, H. M. and Erturan, S., Modified Levelized Cost of Electricity or Energy, MLOCE and Modified Levelized Avoidable Cost of Electricity or Energy, MLACE and Decision Making, American Journal of Modern Energy, 5 (1): 1-4, doi: 10.11648/j.ajme.20190501.11, 2019. 